Meta

Journal des traducteurs

Translators' Journal

\title{
The Evolution of Laurentian University's Undergraduate Program for Translator and Interpreters
}

\section{Ronald Henry}

Volume 30, numéro 3, septembre 1985

URI : https://id.erudit.org/iderudit/003055ar

DOI : https://doi.org/10.7202/003055ar

Aller au sommaire du numéro

Éditeur(s)

Les Presses de l'Université de Montréal

ISSN

0026-0452 (imprimé)

1492-1421 (numérique)

Découvrir la revue

Citer cette note

Henry, R. (1985). The Evolution of Laurentian University's Undergraduate

Program for Translator and Interpreters. Meta, 30(3), 298-305.

https://doi.org/10.7202/003055ar d'utilisation que vous pouvez consulter en ligne. 


\section{THE EVOLUTION OF LAURENTIAN UNIVERSITY'S UNDERGRADUATE PROGRAM FOR TRANSLATORS AND INTERPRETERS}

The object of this paper is to focus on milestones in the development of one translation School's program as regards the various knowledge components that comprise it. These components are understood to encompass those broad areas of the translating profession with which a student must be familiar, as well as the general knowledge needed to develop a sense of intellectual discrimination, and face the employment market or undertake graduate training. The areas of knowledge dealt with are professional education, namely translating, interpreting and terminological research, language and literature, as well as background in the Arts or Sciences.

We will proceed by outlining the program of the School of Translators and Interpreters of Laurentian University at given times over a fifteen year period. This program was originally designed by teachers of modern languages, with the contribution of an experienced translator and teacher by the name of J.F. Hendry, whose pioneering work should be saluted.

Laurentian's translator training program was set up at the undergraduate level. When this program was launched in 1968, the training of translators at this level was a new concept in Canada, where the Université de Montréal had been the only one to offer a translation program at the Master's level since the early fifties. In 1968, Laurentian, Ottawa and Montreal all inaugurated Bachelor's degree programs. These programs all led to the Honour's degree which, in Ontario, means four years of study rather than the three leading to a general Bachelor's after thirteen years of elementary and secondary school education

The decision to teach translation at the undergraduate level, made at Laurentian at a relatively early date is a major step that is still hotly debated in Canadian academe, where many people consider that translators should be trained in graduate schools.

The evolution of this undergraduate program will be examined by commenting on the emphasis placed on the various areas of knowledge mentioned above - namely, education, language and literature and background courses - in 1969, 1971, 1975 and 1983. 
In 1969 , the fledgling program covered the following components of professional education :

a) translation from and into both English and French, as well as other modern European languages (German, Italian, Russian, Spanish);

b) translation of pragmatic material including commercial, legal, scientific and technical, as well as literary translation :

c) a course on documentation and terminology ;

d) the inclusion within the several TRAN courses of précis-writing, conference note-taking and theory.

These are indicative of an honest attempt at identifying the functions of the translation profession, and setting up a program of instruction corresponding to the activities a translator is often called upon to carry out. Indeed, the future development of the program followed largely from this initiative.

One might, however, wonder why the translation courses were clustered at the end of the program, and why there where no such courses in years one and two. The fact is this was already an issue, and it would come to a head before long.

The 1969 program provided for six semielectives to be taken from among Arts and Science offerings : 30 percent of the program was to be taken from among a guided choice of non-language courses. This also was an issue of continuing debate, both as regards the number of electives and as to whether or not their choice should be "directed".

Language (grammar, composition, stylistics and linguistics), literature, and third languages, seen as distinct from translation courses, comprised the largest compulsory component of the program in its early years $(40 \%)$. This derived from the vision of the translator as a polyglot, and from the fact that the School of Translators was born of humanists, primarily professors of literature, and men of European background.

Literature, in whatever language, was not, however, to play a central role in future years.

Over a three-year period, the concept of translator training at the undergraduate level had developed within academic circles, especially among the students. Indeed, two courses in translation over three years had caused much unrest. Students wanted more, and they went on strike to prove their point. Almost half of them left.

In its wisdom - and following some turmoil - the Academic Senate adopted a revised program whereby the number of translation courses more than doubled (from 6 to 13). This allowed for improved articulation of various elements of professional education, and for spreading them out over the four years of the program, much to the satisfaction of students and faculty.

The language and literature courses were reorganized to shift the responsibility for grammar and composition to the translation component, and to strengthen the position of third languages at a time when a merger of the School of Translators and the Department of Modern Languages was thought to be just around the corner.

In the process, the electives were reduced from 6 to 4 . This was a surprising turn of events, since the total number of courses in the translation program was increased from 20 to 24 courses, while all other programs in the University required 20 courses. Was the overall increased course load for students in the translation program a recognition of a stronger caliber of students ? Was it an acknowledgement of the translator's need for a broad cultural background? Or was it due to the suspicion that translation was not as serious an academic pursuit as linguistics or literature, for example? The reason was painfully unclear.

What was beyond a doubt was the severe strain that the doubling of course offerings would impose on a faculty of five, if enrolment increased. And enrolment swelled, from 75 to 235 students (313\%) by 1974 .

By September 1975, the teaching complement had doubled, and two translation courses had been returned to a French Department eager to provide ancillary courses. Terminology had been refined as one of the three main components of the program, along with translation (into English from French and vice versa) and interpretation (compulsory consecutive, optional simultaneous).

The two documentation and terminology courses were now restructured into four half-classes : 1) Documentation and Terminology; Scientific Vocabulary; 2) Commercial and Administrative Terminology; Legal and Political Terminology.

Where interpretation was concerned, the course on conference note-taking had been separated from précis-writing and composition, and was clearly for the purpose of consecutive interpreting. Also, a full-year elective in simultaneous interpreting was added to the fourth-year offerings. (It should be noted that a graduate was not expected to be a fullfledged interpreter, but that he or she would have been screened, as if were, for admission to a graduate diploma program in interpretation. The latter, however, was never born.

Moreover, a parallel program - not in all points identical, indeed completely different in first and second year - had been developed and implemented for the benefit of Francophone students. (In order to keep the presentation as simple as possible, this parallel program will not be discussed here.)

As regards overall structure, one third language course had been dropped, one elective added, and the sixth course eliminated from years two and four. What was most significant was that the School of Translators and Interpreters bowed out of translation into and from third languages.

The decision to concentrate on two languages only was essentially taken for practical reasons. Schools are situated in time and space - they are 
subject to physical constraints, as are even the most abstract thinkers. Laurentian University is a bilingual institution in a bilingual community, in a bilingual country. The two languages are English and French. Moreover, the effects of financial exigency were such that by the mid-1970's, the University community was locked into a scramble for available funds that sensitive colleagues termed academic cannibalism. Retrenchment was deemed necessary, and efforts turned to consolidating a core program focused on the English and French languages. The other modern European languages available (German, Italian, Russian and Spanish) would continue to be taught by the Department of Modern Languages (D.M.L.) and the School would continue to require of its students a minimum of two courses in one same third language. The D.M.L., essentially a department of language and literature, agreed to offer advanced courses enphasizing non-literary translation at some future time. Unfortunately, this was never achieved.

This is the program as it stands as the beginnings of the academic year 1983-1984. Several major changes have taken place since 1975 .

First, a highly regretted loss : the credited practicum supervised by the University's official translator. The translator could not be persuaded to continue for the classic reasons : lack of interest for pedagogical pursuits (marking papers), and lack of supplementary pay to foster an interest.

Second, a reduction of the full course introduction to general linguistics to a half-course, as a result of the recognized need for advanced composition, and the waning appeal of general linguistics as a compulsory component of undergraduate training.

Third, the elimination of the third language requirement, and the concomitant addition of two electives, and the enhanced possibility of including within the four-year B.S.L. (Bachelor of Science in Languages) degree program the equivalent of a major in the liberal arts or sciences.
This last issue, as might be expected, was highly contentious. The leading argument against was that a degree in languages must reflect the study of more than two languages. The main reason for carrying if through was to add flexibility to the program in recognition of that most basic necessity for a translator, a sound general background, preferably as defined by a tried and valued design, the liberal arts (or science) major. In effect, the student in the B.S.L. program at Laurentian University will have the opportunity to include in his four-year 21 course translation program the equivalent of a major in an Arts or Sciences discipline. This, I feel, is the strongest feature offered, since it provides for a thorough background in a subject matter, which is after all what a translator works on, with evaluation of the student's knowledge by specialists in the respective fields.

The concept is simple and straightforward enough to have its detractors, mainly among those people who already have the perfect recipe for all of the ingredients needed to produce the ideal translator. This approach, however, has the advantage of allowing for a variety of specialties among graduates who will have chosen any number of elective disciplines, and as a group therefore will be better equipped to meet the needs of society.

Also, and not of the least significance, this formula meets some of the academic objections to translator training at the undergraduate level regarding a well-rounded general education.

That is the way in which the knowledge requirements (professional education, language and literature, and background in the Arts or Sciences) have been met at the School of Translators and Interpreters at Laurentian University. Our experience has been laborious at times. The achievement of a program yet to be perfected has take what should appear to some a lifetime. It definitely took commitment.

RONALD HENRY 


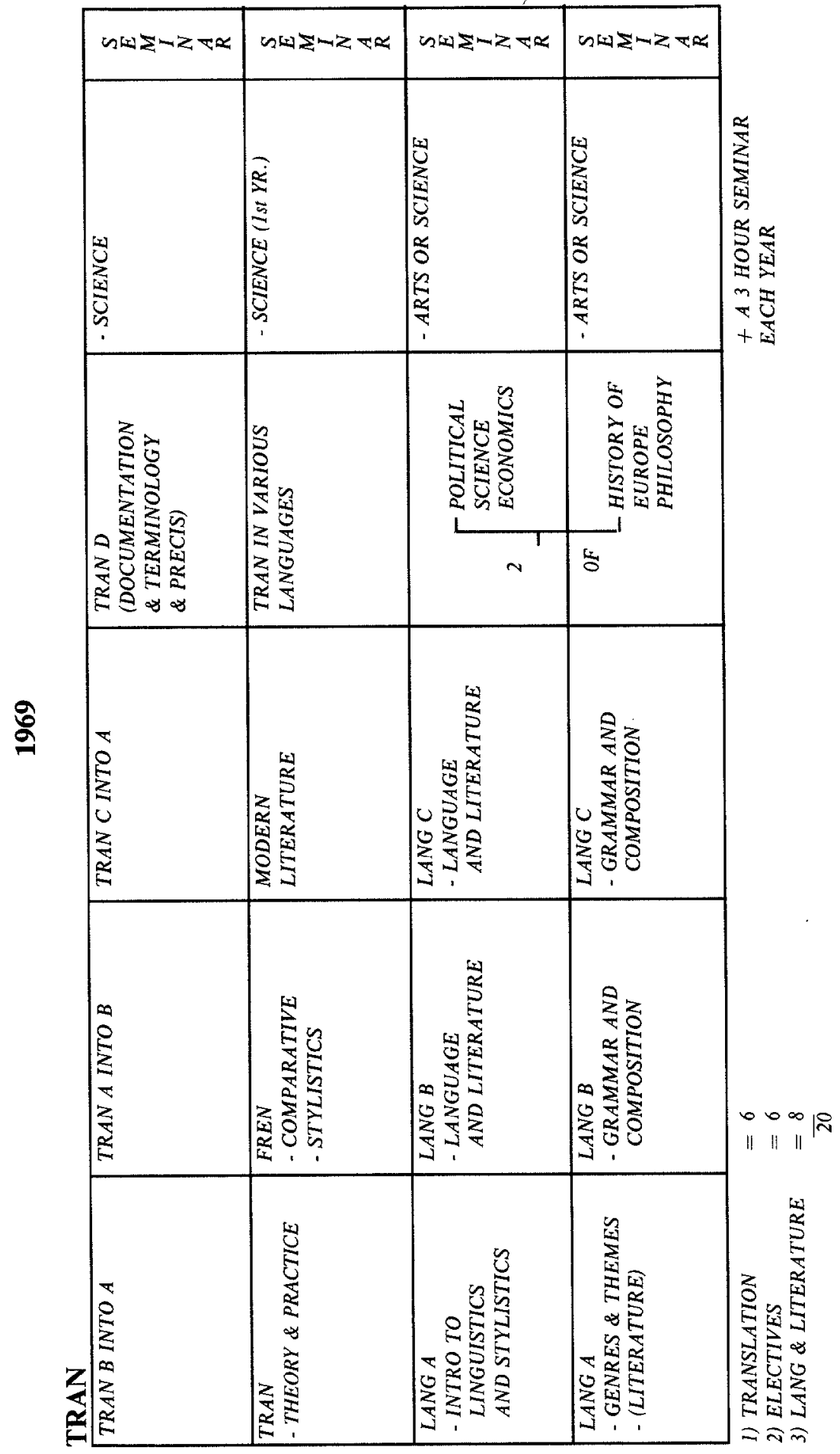




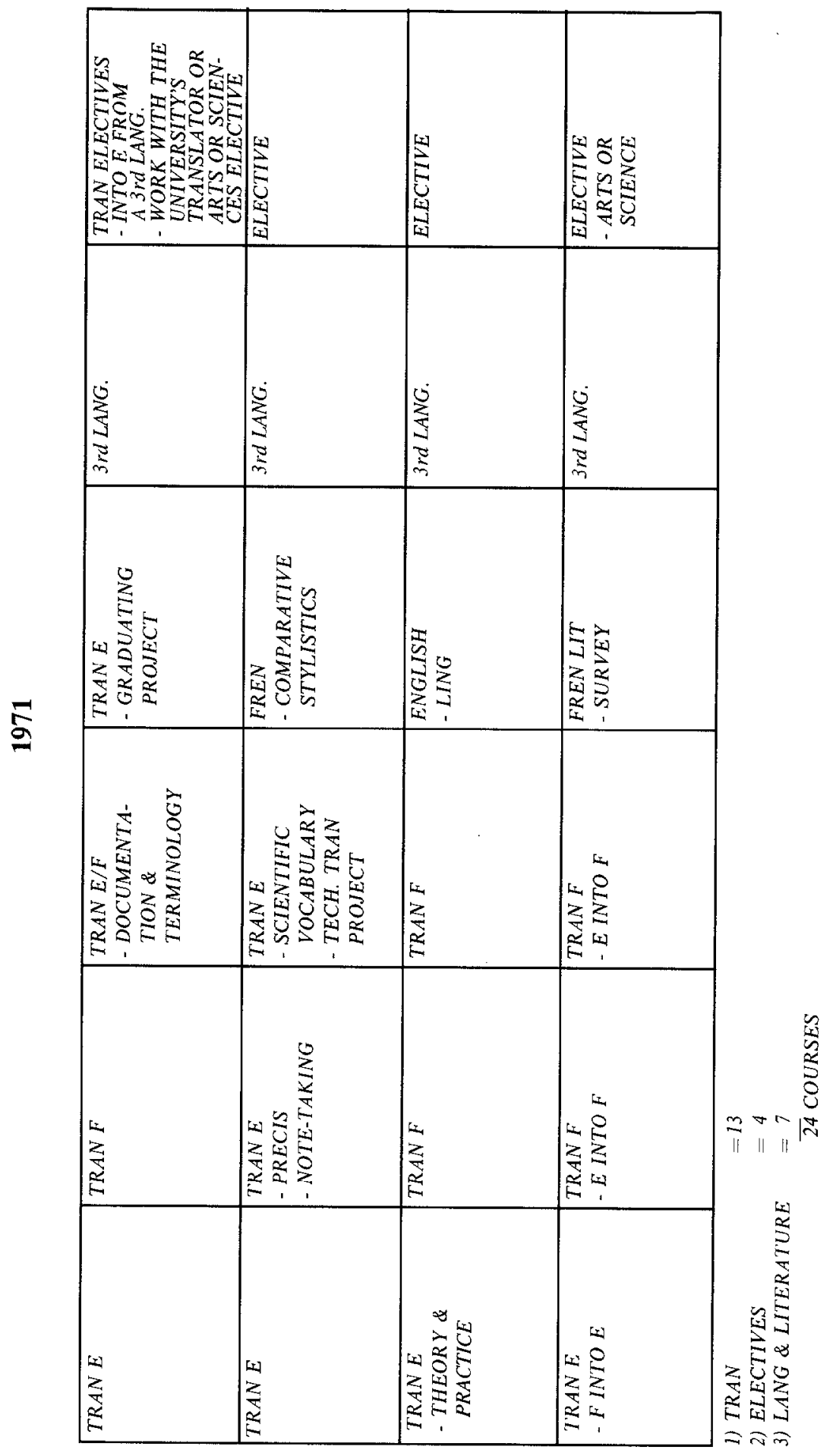




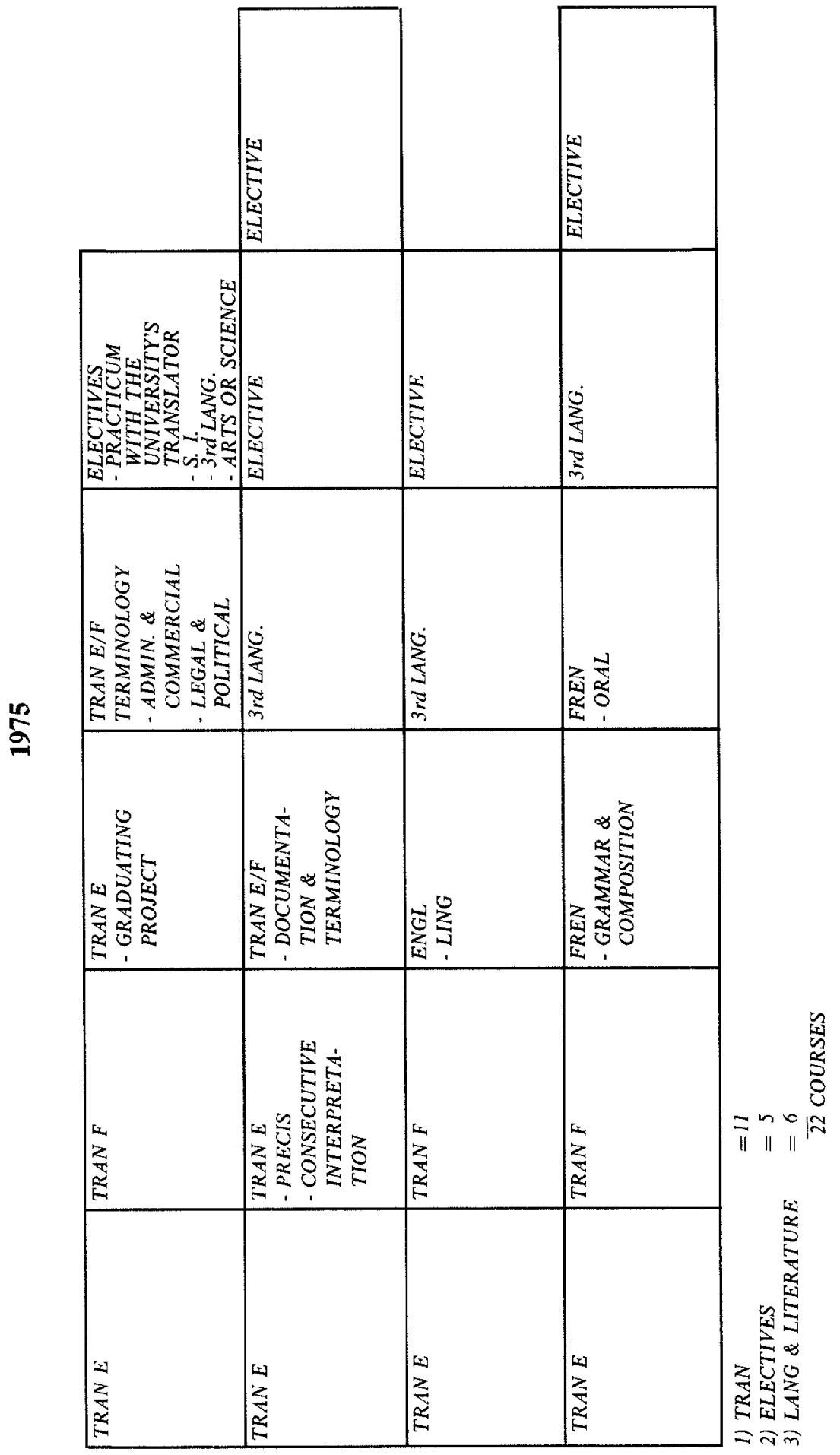




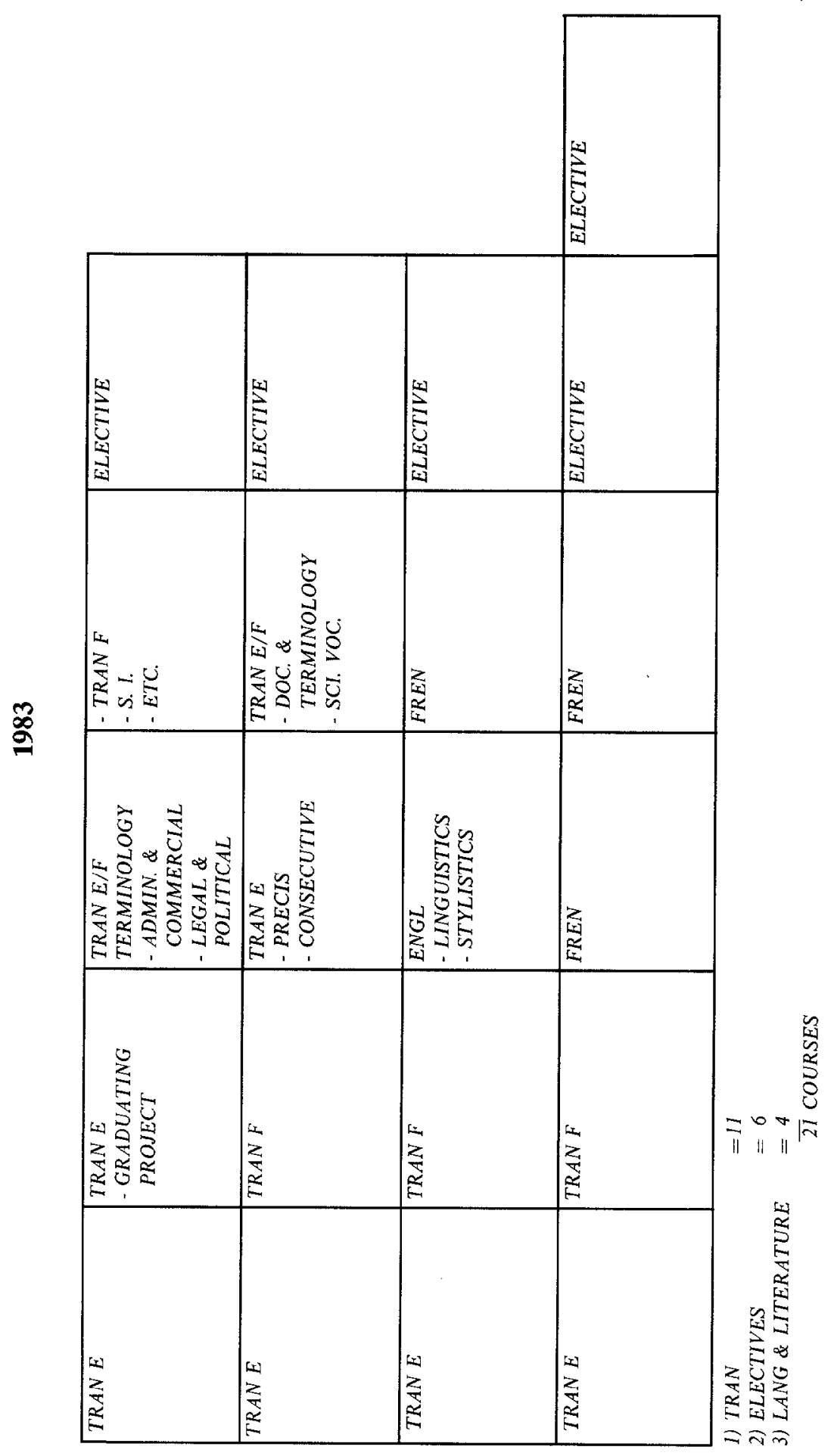




\section{APPENDIX}

Numerical Synopsis of Program Evolution

in Relation to Major Knowledge Area Components

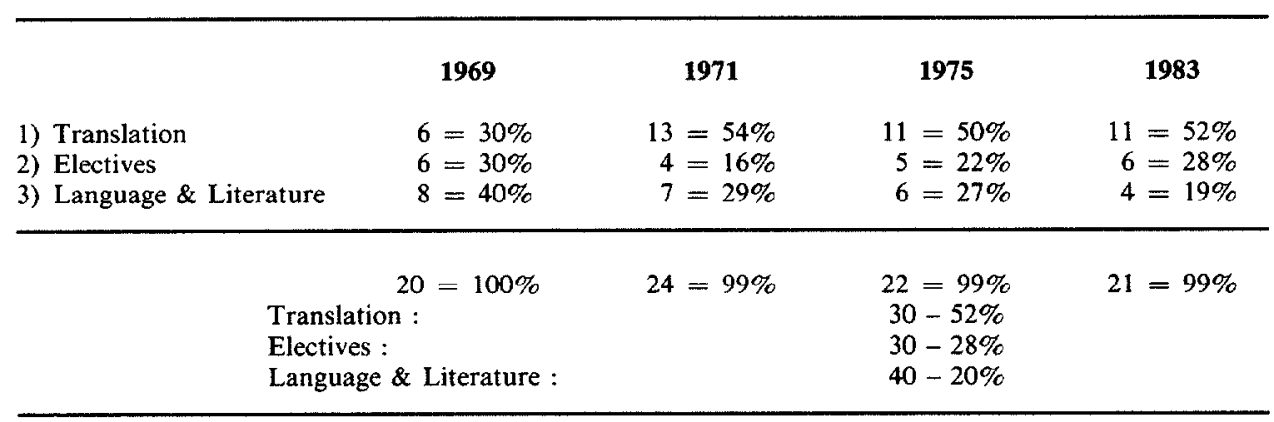

Editor's Note : R. Walter Jumpelt's article "The Conference Interpreter's Working Environment under new ISO and IEC Standards", META, 30-1, March 1985, pp. 82-90, has been published in German in LEBENDE SPRACHEN, Heft 1, 1984. 